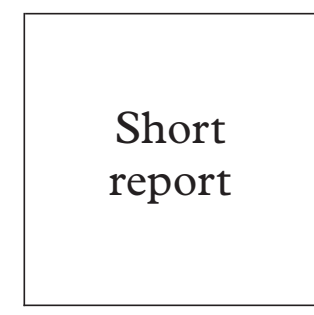

\title{
Recent declines in reported syphilis rates in eastern Europe and central Asia: are the epidemics over?
}

\author{
G Riedner, K L Dehne, A Gromyko
}

Background: Since the early 1990s, major syphilis epidemics have occurred in the Newly Independent States (NIS) of the former Soviet Union. The new and rapidly changing societal and economic conditions in these countries challenge their traditional approaches to the control of sexually transmitted infections (STI). Nevertheless, following a steady increase until 1997, reported syphilis incidence has declined during the past 3 years in most parts of the region. We examine these trends against a background of ongoing changes in service delivery, care seeking behaviour, and case finding practices.

Methods: National syphilis surveillance data reported to the WHO Regional Office for Europe were compiled and analysed, and supplemented with information presented at recent expert meetings and with results from ongoing research.

Results: Since 1997, reported syphilis incidence either stabilised or declined in many locations in the NIS, but further increased in others, especially in rural areas. Congenital syphilis continued to increase in all countries, except Latvia. The proportion of self presenting cases versus cases detected through screening declined, and so did notifications of early compared with late forms of syphilis. Patients increasingly seek care in the private formal and informal healthcare sectors which hardly participate in case reporting.

Conclusions: Recent declines in syphilis notifications in the NIS are at least partially a reflection of a reduced intensity of active case finding and of changes in reporting completeness because of a shift in service utilisation from the public to the private/informal sectors. Syphilis rates are still high, indicating that both public and private sectors have to respond more efficiently to the needs of many people at risk of STI. The collection of serial STI prevalence data is recommended to be able to validate trends in notifications.

(Sex Transm Inf 2000;76:363-365)

Keywords: syphilis; Newly Independent States; sexually transmitted infections

\section{Introduction}

Since the collapse of the Soviet Union, poverty, unemployment, migration, and changes in values and sexual mores put large populations at risk of sexually transmitted infections (STI). The economic decline led to the deterioration of public health services, including those for STI. ${ }^{1-4}$ Between 1990 and 1997 up to 175 -fold increases of syphilis notifications had occurred in eastern European and central Asian countries. ${ }^{1}$ Young and jobless people are most heavily affected ${ }^{36-8}$ with, for instance, incidence among 18-19 year old Russian girls reaching $1.2 \%$ in $1996 .^{5}$ Syphilis notifications started to decline in 1997 throughout the Newly Independent States (NIS). This report reviews those trends in the context of recent changes in service delivery and utilisation.

\section{Data sources}

STI surveillance data in the NIS are the result of mandatory and universal notifications of newly identified cases by diagnosing physicians. Data from state clinics are regarded as complete, while the growing unofficial private sector in many countries does not participate in case reporting. Syphilis notifications combine self reporting cases and cases that are detected through screening and contact tracing. This report draws data from various sources, including official reports from ministries to the World Health Organization and presentations made by local experts at several meetings organised by the WHO during 1998 and 1999.

\section{Syphilis trends during the 1990s}

Reported syphilis incidence increased in the majority of NIS throughout the early 1990s, peaked in 1996 or 1997 and declined thereafter (table 1).

\section{GEOGRAPHICAL VARIATIONS}

The extent of the increase in reported cases in the NIS between 1992 and 1996-7 varied between threefold (in Armenia) to 175-fold (in Kazakhstan). In terms of annual incidence per 100000 population in 1996 or 1997, Russia, Kazakstan, Belarus, Moldova, Kyrgyzstan, and Ukraine were the worst affected, followed by the Baltic States and the Caucasus (table 1).

Within countries there are also enormous variations. For instance, Russia reports syphilis incidence ranging from below 45 per 100000 in Checotah to above 1500 in the remote Tuva Region in 1998. ${ }^{9}$ In Kazakstan incidence ranged from 110 per 100000 in south Kazakstan to 380 per 100000 in north Kazakstan. ${ }^{8}$ While rates have decreased in larger cities since 1996-7, they continued to increase in some rural areas. ${ }^{10}$
Accepted for publication 29 June 2000 
Table 1 Notification rates of newly diagnosed syphilis cases in selected eastern European and central Asian countries 1990-9 (rates per 100 000)

\begin{tabular}{lrrrrrrrrrr}
\hline & 1990 & 1991 & 1992 & 1993 & 1994 & 1995 & 1996 & 1997 & 1998 & 1999 \\
\hline Armenia & 3.7 & 6.9 & 7.1 & 8.7 & 11.2 & 11.9 & 17.4 & 16.7 & 14.2 & 12.2 \\
Azerbaijan & 2.7 & 4.0 & 6.0 & 7.8 & 8.5 & 9.1 & 9.2 & 7.5 & 8.2 & \\
Belarus & 2.7 & 5.1 & 11.8 & 30.3 & 72.1 & 148.9 & 209.7 & 199.1 & 164.1 & 125.5 \\
Bulgaria & 4.3 & 4.8 & 7.4 & 10.3 & 14.4 & 20.2 & 26.8 & 26.0 & 32.6 & \\
Estonia & 3.4 & 7.4 & 11.4 & 22.5 & 65.8 & 69.7 & 66.2 & 71.9 & 75.3 & 58.2 \\
Georgia & 12.8 & 13.6 & 13.5 & 12.1 & 14.1 & 16.3 & 18.7 & 38.9 & 40.2 & \\
Kazakstan & 1.4 & 2.1 & 3.5 & 8.1 & 32.3 & 122.9 & 238.7 & 244.7 & 231.4 & 174.6 \\
Kyrgystan & 2.0 & 2.0 & 2.7 & 4.3 & 22.4 & 72.2 & 152.8 & 167.8 & 144.4 & \\
Latvia & 4.8 & 8.1 & 10.4 & 32.1 & 59.7 & 93.7 & 124.9 & 121.8 & 105.6 & 63.2 \\
Lithuania & 1.9 & 4.8 & 7.6 & 18.6 & 57.6 & 90.9 & 101.4 & 84.9 & 62.8 & \\
Moldova & 15.8 & 20.4 & 46.6 & 83.4 & 118.1 & 174.5 & 201.2 & 187.6 & 150.5 & 115.9 \\
Russian Federation & 5.3 & 7.2 & 13.4 & 33.9 & 85.8 & 177.0 & 264.6 & 277.3 & 225.6 & 187.3 \\
Tajikistan & 1.6 & 1.6 & 2.9 & 4.9 & 7.8 & 14.7 & 18.8 & 19.0 & 16.3 & \\
Turkmenistan & 4.6 & 5.4 & 6.3 & 8.3 & 15.0 & 29.6 & 37.9 & 54.0 & 46.8 & 44.42 \\
Ukraine & 6.0 & 10.1 & 18.8 & 35.1 & 69.2 & 119.0 & 150.9 & 147.1 & 138.4 & 113.9 \\
Uzbekistan & 1.8 & 1.9 & 2.5 & 4.1 & 10.9 & 23.6 & 35.6 & 44.4 & 47.5 & 37.0 \\
\hline
\end{tabular}

Source: WHO Regional Office for Europe, Copenhagen.

Table 2 Notifications of new congenital syphilis cases in selected newly independent states from 1991 to 1998

\begin{tabular}{|c|c|c|c|c|c|c|c|c|c|}
\hline & 1990 & 1991 & 1992 & 1993 & 1994 & 1995 & 1996 & 1997 & 1998 \\
\hline Armenia & & & & 0 & 0 & 0 & 5 & 8 & 12 \\
\hline Azerbaijan & & & & & & & & 7 & 11 \\
\hline Belarus & & & & & & & & & 23 \\
\hline Georgia & & 1 & 1 & 0 & 3 & 1 & 2 & 11 & 20 \\
\hline Kazakstan & & & 0 & 0 & 4 & 52 & 88 & 206 & 294 \\
\hline Kyrgyzstan & & & & & 1 & 12 & 43 & 45 & 67 \\
\hline Latvia & & 1 & 1 & 0 & 2 & 15 & 25 & 22 & 16 \\
\hline Moldova & & & & & 0 & 2 & 2 & 4 & 4 \\
\hline Russian Federation & 15 & 29 & 33 & 75 & 118 & 222 & 470 & 714 & 840 \\
\hline Tajikistan & & & & & & & & & 4 \\
\hline Turkmenistan & & & & & & & & & 5 \\
\hline Ukraine & & & & & & & 71 & 83 & 79 \\
\hline Uzbekistan & & & & & & & & & 3 \\
\hline
\end{tabular}

Source: WHO Regional Office for Europe, Copenhagen.

TRENDS IN THE PROPORTIONS OF ACTIVELY

DETECTED SYPHILIS CASES VERSUS SELF

PRESENTING CASES

Proportions and absolute numbers of symptomatic, self reporting cases decreased in favour of latent cases that are detected through screening. In Russia, for instance, the proportion of symptomatic patients (among all notified cases), who present themselves to state clinics dropped from $41.5 \%$ in 1995 to $32.8 \%$ in $1997^{7}$ and in Kyrgyzstan from 33\% in 1995 to $20 \%$ in $1998 .^{5}$

At the same time, "contact ratios", the number of contacts per index case that are traced and treated declined in several countries. For example in Russia, the contact ratio fell from 1.7 in 1989 to 0.9 in $1998^{7}$ and in Kazakstan from 3.4 in 1991 to 1.7 in $1997 .{ }^{8}$ Russian government officials estimated that about 23000 contacts had not been traced and treated in 1998 in the public health sector. ${ }^{7}$

CONGENITAL SYPHILIS

Congenital syphilis used to be very rare during the 1980s, throughout the region. Since 1990 rising numbers of newborns with congenital syphilis have been reported from most eastern European and central Asian countries. In Russia the number of congenital syphilis cases almost doubled each year from 1992 to 1997, reaching 714 in 1997 , which is equivalent to an incidence of 5.6 per 10000 newborns. In some regions, the incidence surpassed 20 per 10000 newborns, being highest in Tuva Region with 41.8 per 10000 newborns. ${ }^{9}$ Neighbouring countries-for example, Kazakhstan and Ukraine, also report high incidences of 13 and 1.9 per 10000 newborns respectively $^{811}$ (table 2).

SYPHILIS AMONG PREGNANT WOMEN

Syphilis screening for pregnant women is usually provided free of charge in antenatal care services and in Russia and Belarus approximately $95 \%$ of pregnant women make use of those services. Many of those at high risk of STI, teenagers, and those belonging to marginalised populations including the homeless, do not attend, however. In Russia, for instance, $50 \%$ of teenage mothers did not attend for antenatal care in $1997 . .^{\circ}$ Other countries, like Georgia, recently faced problems with maintaining routine syphilis screening during pregnancy owing to shortages of test reagents. ${ }^{12}$

Prevalence data on syphilis among pregnant women are not routinely compiled in the region and therefore few data are available. They show, for example, an exponential increase from 0.02 in 1991 to 0.75 in 1997 in Moscow $^{13}$ and from $0.004 \%$ in 1991 to $0.8 \%$ in 1996 nationwide in Kyrgyzstan. ${ }^{14}$ In 1998, in some regions of Kazakstan, up to $1.6 \%$ of pregnant women had syphilis. ${ }^{15}$

\section{Discussion}

The occurrence of the syphilis epidemics in the transitional societies of the NIS has challenged the traditional approach to STI control inherited from the Soviet Union, which was based on such infectious disease control principles as the early active detection of cases and their hospitalisation until cure. It was implemented through a vertical network of dermatovenereology services, which provided diagnosis and 
treatment and was responsible for tracing and treating of sexual partners, extensive screening programmes among clinically and occupationally defined population groups, as well as compulsory notification of cases. During the 1990s economic constraints forced STI services to rationalise their extensive diagnostic testing and screening activities. Patients themselves increasingly avoided the stigma and sanctions associated with public venereology clinics and found more convenient alternatives in the emerging official and unofficial private sector. Consequently public services introduced changes to become more client friendly. Outpatient treatment and (paid) diagnostic services on an anonymous basis are being offered.

Since 1997-8, case notifications have declined throughout the region. As case notification rates are highly sensitive to the intensity of active case finding, in health service utilisation and in case reporting the decline must be interpreted with caution.

In fact, there is evidence from healthcare seeking behaviour studies in Kazakhstan and Belarus that people with STI symptoms have sought care from private (licensed and unlicensed) providers during recent years. ${ }^{16}$ In the case of syphilis this is facilitated by the easy availability of benzathine penicillin allowing for a "one shot" treatment.

Active case finding through screening programmes and through partner tracing continues to contribute more than $50 \%$ to the total number of reported syphilis cases in many countries-but in several of them either screening (in Georgia) or contact tracing (in Russia and Kazakhstan) has significantly diminished.

The reported increase of congenital syphilis is a case in point, as there are obviously an increasing number of pregnant women without adequate antenatal care. Congenital syphilis, once suspected, is almost exclusively treated in paediatric clinics, which are state run. It is, therefore, likely that congenital syphilis reporting is more complete than adult syphilis reporting.

On the other hand there are features of the syphilis notification data that suggest that the syphilis epidemic may be self limited and that transmission may have peaked between 1996 and 1998. They include: (1) the relative increase in the proportion of later versus earlier stages of the disease; and (2) the diverging trends in urban versus rural areas. The latter may indicate that a saturation of infections in population groups at risk occurred earlier in towns than in rural areas.

\section{Conclusion}

Although syphilis notifications have peaked in most NIS in 1996 and 1997, changes in treatment seeking behaviour, service utilisation, the intensity of active case finding and reporting are likely to distort true trends. For a better understanding of epidemiological trends and in order to validate case reporting data, prevalence surveys should urgently be incorporated into the surveillance systems.

Congenital syphilis is still on the increase and, though declining, adult rates remain high. The STI prevention and care system urgently needs to respond more effectively to the needs of people with and at risk of STI.

We are grateful to health ministries in Eastern European and Central Asian countries and their representatives for the provision of national surveillance data and valuable background information for their interpretation during meetings and workshops held by WHO during 1996 to 2000

Contributors: GR contributed to the collection of data, their analysis, and interpretation. She produced drafts and revised analysis, and interpretation. She produced drafts and revised them according to the co-authors' comments; K-LD participated in the collection of the data and their interpretation. He contributed to the conception of the article and revised several
drafts; AG participated in the collection of the data and their interpretation and revised the penultimate version.

1 Barr AB, Field MG. The current state of health care in former Soviet Union: implications for health care policy and reform. Am F Public Health 1996;86:307-12.

2 Tichonova L, Borisenko K, Ward $\mathrm{H}$, et al. Epidemics of syphilis in the Russian Federation: trends, origins and priorities for control. Lancet 1997;350:210-13.

3 Osmonaliev MK, Nurgasieva DT, Shapiro BM, et al. Incidence of STD in the Kyrgys Republic and the implementation of interventions according to WHO recommendations. Presentation at the meeting on an integrated approach to the prevention and treatment of STIs, St Petersburg, 12-14 May 1999.

4 Babayan K. Efforts to co-ordinate with women's reproductive health for the control of STDs in Armenia. Presentation at the meeting on an integrated approach to May 1999.

5 Gromyko A. Trends of HIV/AIDS and STI in eastern Europe. Presentation the meeting on an integrated approach to the prevention and treatment of STIs, St Petersburg, 12-14 May 1999

6 Renton A, Borisenko K. Epidemic syphilis in the newly independent states of the former Soviet Union. Curr Opin Infect Dis 1998;11:53-6.

7 Tichonova L. Epidemiology and control of syphilis in the Russian Federation. Presentation at the meeting on an integrated approach to the prevention and treatment of STIs, St Petersburg, 12-14 May 1999.

8 Kesheleva Z. STI control in Kazakhstan. Presentation at the fourth meeting of the STI Task Force for eastern Europe and central Asia, Copenhagen, Denmark, 10-11 February 2000 .

9 Borisenko K, Tichonova L, Toskin I. Improvement of the epidemiological situation regarding curable STI in the Republics of Khakassia and Tuva, East-Siberian Region of the Russian Federation. Presentation at the meeting on an integrated approach to the prevention and treatment of STIs, St Petersburg, 12-14 May 1999.

10 Shouvalova T. Syphilis incidence trends in Moscow Region. Presentation at the meeting on an integrated approach to the prevention and treatment of STIs, St Petersburg, 12-14 May 1999.

11 Kaluznaya L. Presentation at the 2nd meeting of the Task Force for the Urgent Response to the Epidemics of Sexually Transmitted Diseases in Eastern Europe and Central Asia, Vilnius, Lithuania, 22-23 September 1998.

12 Khotenashvili L. Presentation at the 2 nd meeting of the Task Force for the Urgent Response to the Epidemics of Sexually Transmitted Diseases in Eastern Europe and

13 Shouvalova TM, Tumanyan AG, Yudakova VM. Trends in the epidemiology of syphilis among pregnant women in Moscow Region, Russian Federation. Sex Transm Dis (Russian) 1999;1:20-3

14 Riedner G. Report on a mission to Kyrghyzstan. Copenhagen: WHO Regional Office for Europe, June 1997.

15 Kossukhin A. Assessment of the situation of the syphilis epidemic. Draft report to UNAIDS. Almaty, Kazakhstan, 1999.

16 Riedner G. Health care seeking behaviour for sexually transmitted infections in Almaty, Kazakhstan. Study report. Copenhagen: WHO Regional Office for Europe, June 2000 